opioid analgesics, $8 \%$ sold stimulants and $1 \%$ sold barbiturates; $89 \%$ of them did not require a prescription and only $3 \%$ indicated that, before they dispensed a medicine, a prescription would be required (National Center on Addiction and Substance Abuse, 2006). In 2006, 34 illegal internet pharmacies dispensed more than 98 million dosage units of hydrocodone products (International Narcotics Control Board, 2008). In the USA, the law enforcement authorities examined 1153 imported parcels containing medicinal products during a 3-day operation in 2003. The overwhelming majority of the products (88\%) were illegally imported drugs, including more than 25 different controlled psychotropic medicines, such as diazepam and codeine (Food and Drug Administration, 2003).

\section{Law enforcement and cooperation}

According to a study conducted by the World Health Organization (2003), in 30\% of countries drug regulation is either non-existent or very limited. Clandestine manufacture and trafficking are facilitated by weak drug regulations, weak enforcement of existing regulations and lenient penal sanctions for counterfeiters. If sanctions are not commensurate with the enormous profits that are made, they do not serve as a sufficient deterrent.

Effective action requires the existence of competent national drug regulatory authorities, with a sustained resource base, to ensure control and regular inspection of those involved in the manufacture, trade and distribution of pharmaceuticals.

To regulate the medicines market effectively, national drug regulatory authorities require political will, relevant legislation, appropriate organisational capacity and skilled professionals. The training of healthcare professionals should include guidance on how to promote the rational use of medicines in general and psychotropic medications in particular. Codes of conduct for associations of healthcare professionals, industry and chambers of commerce should address the issue of incorrect or improper handling of drugs. Drug regulatory authorities, law enforcement agencies, manufacturers of pharmaceuticals, professional associations of medical practitioners and pharmacists, as well as consumer protection groups, need to work in concert to identify counterfeit medicines that are in national distribution channels and their sources, so that adequate preventive measures can be undertaken. Without the cooperation of all concerned, there will be little chance to overcome this problem.

These actions at national level need to be complemented by strengthened, concerted international preventive and investigative efforts. National drug regulatory authorities should cooperate effectively in eliminating counterfeit medicines from international commerce. Cooperation and intelligence sharing among national drug regulatory and law enforcement authorities would help to stop shipments of counterfeit medicines and would facilitate the arrest of persons engaged in counterfeiting. Furthermore, national drug regulatory authorities should cooperate with the International Medical Products Anti-Counterfeiting Taskforce, set up with the Declaration of Rome of 18 February 2006. Governments need to be appropriately sensitised to the health and economic risks associated with the counterfeiting of medicines, so that appropriate laws against counterfeiting are enacted, and resources and infrastructure are provided for effective law enforcement at national level.

Apart from governments, the pharmaceutical industry, professional organisations, consumer associations and healthcare professionals, mass media and particularly the health and medical journals all have an important role to play in public education. Psychiatrists, particularly through psychiatric and mental health societies and associations, have a pivotal role to play in relation to the appropriate use of psychotropic medicines, which should include education of both patients and their carers in the risks associated with the use and misuse of medicines, especially those from unregulated sources.

\section{References}

Food and Drug Administration (2003) Customs import blitz exams reveal potentially dangerous import drug shipments. FDA News, 29 September.

International Narcotics Control Board (2008) Report of the International Narcotics Control Board for 2007. United Nations. Available at http:// www.incb.org/incb/en/annual-report-2007.html

National Center on Addiction and Substance Abuse at Columbia University (2006) 'You've Got Drugs!' Prescription Drug Pushers on the Internet: 2006 Update. CASA White Paper.

World Health Organization (2003) Effective Medicines Regulation: Ensuring Safety, Efficacy and Quality. WHO Policy Perspectives on Medicines No. 7. WHO.

World Health Organization (2006) Counterfeit Medicines. Fact Sheet No. 275. WHO. Available at http://www.who.int/mediacentre/factsheets/ fs275/en/

\title{
Migration and psychiatric adjustment
}

\section{David Skuse}

Behavioural and Brain Sciences Unit, Institute of Child Health, London WC1 1EH, UK, email d.skuse@ich.ucl.ac.uk

$\mathrm{W}$ ith the extraordinarily large movements of populations from some of the former Soviet Union states into Western Europe, since their recent membership of the European Union, attention has been focused in recent years on how easy or otherwise it has been for these people to adjust to life in very different economic and social circumstances. It has been estimated that the UK has absorbed up to a million immigrants from Eastern European states 
since 2004, and an equivalent picture is seen elsewhere; for example, in Switzerland immigrants now comprise nearly a quarter of the population. We consider here the mental health issues faced by those moving to work in other countries, some of whom aim to become citizens, others to gain temporary economic advantage, and yet others to escape persecution and threats to their personal safety in their countries of origin.

Solvig Ekblad considers the situation in Sweden, where the immigrant population now comprises about $12 \%$ of the total: as she indicates, there have in recent years been several waves of immigration from the 15 republics of the former Soviet Union, and from Eastern Europe, with many women coming in the hope or expectation of marrying Swedish men. Perhaps surprisingly, those from Poland and other Eastern European states are at far higher risk of psychiatric disorder than immigrants from countries that had been Soviet republics, although all are at risk of poorer physical health than the native Swedes. The Swedish system of immigrant management has been criticised by the United Nations for failing to provide adequate support for the physical and mental wellbeing of vulnerable groups.

In the Canadian immigrant population, there is an overrepresentation of those living below the poverty line, as discussed by Stephen Kisely. He, like Dr Ekblad, emphasises the importance of providing adequate support. This includes mental and physical healthcare. As in Sweden, some Canadian provinces do not automatically provide levels of care that are similar to those accessible by the native population. This may be motivated by a desire to discourage those whose reason for coming is to obtain specific treatments for an existing condition. Mental health seems to be better among those who settle in urban areas, for reasons that are at present speculative. There are significant differences in the approach to the management of immigrant health across the Canadian provinces, which have a degree of autonomy in this respect. Manitoba seems to set a high standard, in the opinion of Dr Kisely, to which other provinces might aspire.

Finally, we have an interesting review of research into the psychological adjustment of young refugees, which summarises the findings from a report on the well-being of young asylum seekers, prepared by Winnie Lau and Trang Thomas from Australia. They point out the important fact that nearly half the world's refugees are children and adolescents. Here we have a very different situation to that facing economic migrants, for these people are escaping situations replete with threat and often overt trauma. Drs Lau and Thomas argue that we ought to be aware that many such children may have symptoms that are indicative of post-traumatic stress disorder, although these may not at first be obvious, even to their parents. Fortunately, over time they do seem to adapt to life in their new country, but even so the prevalence of mental health problems in the children of refugees and asylum seekers is much higher than in the indigenous population. We should not only be aware of this situation but, as concerned psychiatrists, we should be pressing for services to be made available to such children in order to facilitate their adjustment and acculturation. There is naturally a greatly enhanced risk to those who migrate unaccompanied by parents, especially boys who were former child soldiers. It seems there are still considerable gaps in our knowledge about the practical solutions to these pressing problems, although we do know that certain governmental policies, such as mandatory detention, are likely to exacerbate them.

\title{
Mental health among recent immigrants to Sweden from Eastern Europe and the former Soviet Union
}

\author{
Solvig Ekblad PhD
}

Associate Professor in Transcultural Psychology, Stress Research Institute, Stockholm University, email Solvig.Ekblad@stressforskning.su.se

\footnotetext{
Ceveral European states such as Sweden have become

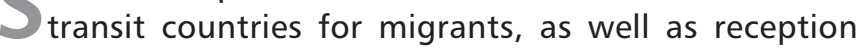
countries for an increasing number of young migrants, not only asylum seekers and refugees from beyond Europe but also from the European Union's new members, after the dissolution of the Soviet bloc in 1989 and then the Soviet Union itself in 1991. Over 110000 immigrants from Eastern Europe and the former Soviet Union resided in Sweden in 2002, although the exact figure is difficult to estimate because of the varied legal status of the migrants. International migration is not a new phenomenon in this part of the world, of course: people have
}

always moved in the search of greater personal safety, among other reasons. However, new groups with new psychosocial needs and demands on the healthcare systems of the host countries will be a challenge. The aim of this article is to give an overview of three sets of empirical data:

$O$ the prevalence of mental disorders among recent immigrants to Sweden from Eastern Europe and the former Soviet Union

their access to mental health and social care facilities arising from their legal status

o their utilisation of health and social services. 